\title{
SUB-REPRESENTAÇÃO DAS MULHERES NA POLÍTICA NO BRASIL: REFLEXOS DE UMA CULTURA PATRIARCAL?
}

\author{
Maria Mary FERREIRA \\ Universidade Federal do Maranhão; UNESP/FCLAr. \\ mmulher13@hotmail.com
}

\begin{abstract}
Resumo
Esta investigação, de cunho teórico, busca refletir a sub-representação feminina no Brasil e de que forma a cultura patriarcal contribuiu para reforçar a atual exclusão das mulheres na política brasileira. Ao longo da construção do Estado brasileiro, as mulheres foram alijadas dos espaços de decisão. Políticas Públicas implementadas nos governos de Luiz Inácio Lula da Silva favoreceram a ascensão de Dilma Rousseff, porém, o conservadorismo e o patriarcado renovado nas relações políticas conservadoras que marcam a vida do Congresso Nacional, conduzidos pela elite, sustentados pela mídia, pelos setores do judiciário e pelas bancadas fundamentalistas, contribuíram para o retrocesso político que culminou com o golpe de 2016 . O desdobramento desse golpe se faz sentir na eleição de 2018 quando os brasileiros optaram por um projeto ultraconservador, tendo em vista que o Presidente eleito representa um projeto que anula os ganhos políticos conquistados no período de 2013-2015. Os dados que ilustram esse estudo são parte de pesquisa de campo realizadas em 2006 , 2010, 2014 e 2016, que permitem confrontar os indicadores do Tribunal Regional Eleitoral disponíveis através de reflexões e análises de matérias jornalísticas colhidas na mídia.
\end{abstract}

Palavras-chave: Patriarcado; Gênero; Sub-representação; Dilma Rousseff; Brasil.

\begin{abstract}
This theoretical research seeks to reflect the female under-representation in Brazil and how the patriarchal culture contributed to reinforce the current exclusion of women in Brazilian politics. Throughout the construction of the Brazilian State, women were left out of decision spaces. Public policies implemented in the governments of Luiz Inácio Lula da Silva favored Dilma Rousseff's rise, but conservatism and renewed patriarchy in conservative political relations that mark the life of the National Congress, led by the media-supported elite, the judiciary and by the fundamentalist congressional benches, contributed to the political setback that culminated in the 2016 coup. The split of this coup is felt in the 2018 election when the Brazilians opted for an ultra conservative project, since the President-elect represents a a project that nullifies the political gains made in the period 2013-2015. The data that illustrates this study are part of the field research carried out in 2006, 2010, 2014 and 2016, which allow comparisons with available TRE indicators with reflections and analyzes of journalistic material collected in the media.
\end{abstract}

Key words: Patriarchate; Genre; Sub-representation; Dilma Rousseff; Brazil.

\section{Introdução}

A eleição de Dilma Rousseff, em 2010, para o principal cargo de poder no Brasil, criou a falsa imagem de que o país, no Século XXI, alcançou patamares de igualdade de gênero. Porém, o impeachment que destituiu a presidenta Dilma Rousseff do poder demonstra que a democracia no Brasil nunca foi consolidada e a igualdade de gênero é um projeto distante de ser concretizado. $O$ 
processo que culminou com o golpe foi coberto de falhas, fazendo emergir um discurso conservador, patriarcal e machista que se acirrou, ainda mais, nas eleições de outubro de 2018, favorecendo a vitória do candidato ultraconservador Jair Bolsonaro, do PSL.

O desgaste promovido pela mídia nacional ao governo de Dilma Rousseff, desde a sua posse, em janeiro de 2014, não se resumiu apenas as críticas à sua política econômica. Foram disseminadas de forma negativa imagens que expuseram a presidenta em muitas situações vexatórias, pouco convencionais, mostrando imagens de desequilíbrio e insegurança.

O desdobramento do golpe, ou as consequências do mesmo, trouxeram à tona a vitalidade do patriarcado expresso nos discursos e ações do presidente empossado, Michel Temer que, ao assumir o cargo, não nomeou nenhuma mulher para os ministérios e proferiu declarações que evidenciaram a visão conservadora do grupo que hoje comanda o país. O impeachment da presidenta Dilma Rousseff fez emergir o debate sobre o patriarcado e as dificuldades das mulheres em ascender ao poder. Por essa razão, o debate sobre as categorias "sub-representação" e "patriarcado" são pertinentes para compreender a dimensão do golpe de 2016 no Brasil, e analisar como a cultura machista e patriarcal que perpassam a vida política brasileira incide sob a sub-representação das mulheres nos espaços de poder ao criar no imaginário social a ideia de que as mulheres não são afeitas ao poder, ou não tem as qualificações adequadas para dirigir os destinos do país, fato que não se justifica em virtude das brasileiras terem mais tempo de estudo e serem hoje a maioria nos cursos de mestrado e doutorado, estão portanto aptas a assumirem cargos na gestão pública, assim como na privada.

A forma como foi forjada a ideia de que Dilma não tinha capacidade para comandar o Estado, demonstra que a cultura patriarcal, machista e misógina foi construída pela imprensa e pela elite brasileira, delineada enquanto branca, racista, excludente e machista. As matérias jornalistas e os discursos veiculados na mídia traduzem essa visão que se espraiou na sociedade brasileira, de norte a sul do Brasil, através de veiculações nas Revista Veja, Folha de São Paulo, Revista Época, Rede Globo e seus diversos canais de comunicação, Rádio Jovem Pan, principalmente. Esses canais de comunicação trabalharam diuturnamente para enfraquecer o governo de Dilma Rousseff, com a perspectiva de construir o golpe. Observamos, a partir de um conjunto de matérias analisadas, que a ação da mídia direcionada para desgastar a imagem da Presidenta teve um efeito devastador, além de forjar o golpe, contribuiu para a desvalorização das mulheres na política. Considero também que o número pouco expressivo de mulheres eleitas, em 2014, para os cargos de deputadas estaduais, federais e senado, também refletiu o desgaste da Presidenta eleita e a exposição das mulheres, principalmente naquelas que tiveram atuação mais aguerrida no parlamento, veja os exemplos da deputada Maria do Rosário e da senadora Gleici Hoffmann, do Partido dos Trabalhadores e da senadora Vanessa Grazziotin do Partido Comunista do Brasil, que foram agredidas em muitas situações no Congresso.

A proposta desse estudo é refletir sobre a sub-representação das mulheres na política do Brasil. Nessa comunicação buscamos discutir dois conceitos chaves: cultura patriarcal e subrepresentação das mulheres no contexto da sociedade brasileira, para assim contribuir com o debate sobre os rumos que tem tomado esse país na última década. Trata-se de um estudo qualitativo, 
construído a partir de dados de pesquisas que desenvolvo no Brasil e em especial no Maranhão com foco nas relações de gênero, no feminismo e na cultura.

\section{Sub-representação das Mulheres no Brasil: um diálogo com as categorias patriarcado e sub-representação feminina para refletir sobre os paradoxos de uma democracia interrompida e inconclusa}

Para compreender como essas relações se mantêm na política brasileira, trago algumas reflexões sobre o conceito de patriarcado que explicam a permanência de relações desiguais, hierarquizadas e a naturalização da violência contra as mulheres, que perpassa a vida privada e se insere na vida pública, cerceando o direito das mulheres de exercerem a cidadania.

\subsection{Patriarcado: uma categoria que explica a exclusão de mulheres na Política}

A categoria patriarcado, na última década, vem sendo recuperada pelas pesquisadoras e estudiosas feministas e tem provocado inúmeros debates nos movimentos em virtude de ser um conceito estratégico para explicar a permanência das relações de subalternidade que mantém as mulheres subordinadas às relações de violência. Essa categoria explica, em grande parte, como as mulheres são levadas a se submeterem a situações de violência, tendo em vista que o maior número dessas violências se efetivam nos espaços domésticos ou privados. Seus reflexos, entretanto, perpassam essas esferas para se inserir na vida pública criando mecanismos que irão excluir as mulheres dos espaços de decisão e de poder.

Ao buscar um entendimento de como o patriarcado se proliferou no mundo ocidental, alimentou-se e se mantém vivo nos dias atuais, encontramos nos estudos da Mary Wollstonecraft algumas explicações que merece uma atenção maior de nossa parte. Quando escreveu seu livro "Reinvindicação dos Direitos das Mulheres", a autora já nos alertava sobre o problema, no Século XVIII. O livro reflete como as mulheres foram excluídas da vida social e pública na Inglaterra. No debate apresentado, a autora faz severas críticas ao pensamento de Jean Jacques Rousseau que considerava as mulheres incapazes de exercer cargos na vida pública, sua visão sobre as mulheres é extremamente conservadora e patriarcal, vejam o que dizia a autora:

[...] Rousseau declara que uma mulher não deveria, nem por um momento, sentir-se independente, que ela deveria ser governada pelo temor de exercitar sua astúcia natural e feita uma escrava coquete, a fim de tornar-se um objeto de desejo mais sedutor, uma companhia mais doce para o homem, quando este quiser relaxar. [...] Que bobagem! Quando surgirá um grande homem com força mental suficiente para dissipar a névoa que o orgulho e a sensualidade têm espalhado sobre o assunto? Se as mulheres são, por natureza, inferiores aos homens, suas virtudes devem ser as mesmas em relação à qualidade, se não ao grau, ou então a virtude é uma ideia relativa; consequentemente, sua conduta deveria ser fundamentada nos mesmos princípios e ter os mesmos objetivos. (WOLLSTONECRAFT, 2016, p. 47).

Como podemos observar a partir da crítica de Wollstonecraft, a visão da sociedade sobre as mulheres, expressa nas palavras de Rousseau, é que ela era vista como um ser inferior que tinha 
como única função servir aos desejos dos homens, entretê-los, obedecê-los, sofrer calada as injustiças:

[...] Os homens dependem das mulheres somente por conta de seus desejos; as mulheres dependem dos homens em virtude tanto dos desejos como de suas necessidades, Nós poderíamos viver melhor sem elas, do que elas sem nós. [...] A primeira e mais importante qualificação em uma mulher é uma boa natureza ou a suavidade de caráter: formada para obedecer a um ser tão imperfeito como o homem, frequentemente cheio de vícios e imperfeições, ela deve aprender cedo até mesmo a sofrer injustiças e suportar os insultos de um marido sem se queixar; não em consideração a ele, mas a si própria, ela deve ter um temperamento aprazível (ROUSSEAU apud WOLLSTONECRAFT, 2016, p. 109-113).

As falas desse pensador, considerado um dos grandes intelectuais do Século XVIII, autor de obras de referência como "O Contrato social" reproduz o conservadorismo da sociedade da época sobre as mulheres. Seus escritos aprofundam a visão patriarcal e preconceituosa que foi forjada sobre as mulheres ao longo dos séculos XVIII, XIX e XX e se espraia no Século XXI tendo em vista os indicadores de violência de gênero e a sub-representação das mulheres na política. É equivocado pensar que o domínio dos homens sobre as mulheres é algo natural, próprio da condição sexual de cada um. Na verdade, o patriarcado tem sido uma construção histórica. Foi construído cultural, social, política e economicamente durante muitos séculos, à medida que as sociedades humanas tornavamse mais elaboradas e complexas. Embora milenar, não deixou de existir, ao contrário, renovou-se e isto é perfeitamente visível nos escritios de Rousseau, e fortaleceu-se conforme as sociedades avançaram na modernidade. Os dados eleitorais retraram este fortalecimento quando em grande parte das nações as mulheres estão subrepresentadas.

Ao analisar a situação das mulheres nas esferas públicas, observamos que muitos países vêm alterando as relações patriarcais no âmbito dos espaços de poder e decisão, principalmente na esfera dos legislativos, porém, é visível que a sociedade concentrou o poder nas mãos dos homens, são eles que dominam a economia e a política na maior parte dos países do mundo, embora tenhamos exceções em alguns países como Alemanha, cujo comando político está sob a responsabilidade de Angela Merkel há mais de uma década.

O patriarcado se manifesta na política quando são os homens que assumem os principais cargos de decisão no mundo público: deputado, senador, vereador, gerente de loja, reitor das universidades, secretários de estado, donos dos grandes empreendimentos econômicos, gerente dos postos de gasolina e dos supermercados, ou seja, os homens estão à frente da maior parte dos negócios, empreendimentos, decisões políticas, assim como na vida privada ao assumir a posição de "dono", "senhor", julgam-se proprietários das mulheres, assim como dos filhos, das suas empresas e dos bens que possuem. No privado a palavra final, em geral, é dada ao homem que decide os destinos da família. Assume, como enfatiza Saffioti (1996, p.37), "a posição de caçador, comportamse como sujeito desejante em busca de sua presa". É o seu desejo e vontade que prevalece e as mulheres, em muitas situações, se submetem.

Esse comportamento desviante não foi adquirido com o nascimento, porque nenhum homem nasce violento, dono da verdade, e senhor das mulheres, enfatiza Saffiotti (1987) esse senso de dominador foi desenvolvido pela cultura patriarcal que ensina aos meninos desde cedo a ter posições 
de mando, desde cedo são ensinados a serem determinados e a dominar, inclusive as mulheres. É por meio desse tipo de cultura que a sociedade incute nos homens e nas mulheres os valores da dominação, da submissão e da subordinação, conforme enfatiza Biroli (2018, p. 43).

As relações de autoridade que produzem a subordinação das mulheres são tecidas por múltiplos fatores. A dupla moral sexual, a tolerância à violência que as atinge por serem mulheres, a ideologia maternalista e os limites para o controle autônomo de sua capacidade reprodutiva são alguns deles. A divisão sexual do trabalho apresenta-se como variável específica (ainda que não independente), determinante para compreensão de como se organizam as hierarquias de gênero.

A situação de subalternidade das mulheres forjada na sociedade patriarcal contribuiu para que sua voz não tenha ressonância. Suas falas e expressões aparecem apenas quando estão sob delegação de algum cargo de poder, (reitora, senadora, deputada, vereadora, delegada, gerente, chefe de setor), ainda assim, é com muito esforço que suas vozes repercutem. O machismo exacerbado impede que as mulheres sejam ouvidas, consideradas iguais e com capacidade e determinação para definir rumos, caminhos para a sociedade. É como se estivessem sempre seguindo a sina descrita na fala de Pitágoras quando declara: "uma mulher em público está sempre deslocada".

Essa situação de subalternidade incide sobre as atribuições sociais das mulheres contribuindo para que o masculino se sobreponha ao feminino. O exemplo mais claro desta situação foi o impeachment da Presidenta Dilma Rousseff, usurpada de seu mandato por um golpe, capitaneado por homens, brancos e ricos que ocupam a maior parte das cadeiras do Congresso Nacional sob a justificativa de um "crime" denominada de "pedaladas fiscais" que todos os ex-presidentes que a antecederam já haviam cometido e o mais grave ainda, o presidente que a sucedeu legalizou o "crime" em uma clara afronta a inteligência dos brasileiros e brasileiras. A violência sofrida por Dilma Rousseff, reflete em todas as mulheres. Não é por acaso que os índices de estupros e feminicídios, aumentaram assustadoramente após o golpe.

O conceito de patriarcado explica a sujeição das mulheres tendo como princípio o exercício do poder dos homens, construído a partir das relações de dominação. Pode ser compreendido como um sistema de dominação e exploração das mulheres pelos homens desde o controle de sua sexualidade, perpassando os espaços públicos e privados a partir das estruturas de poder que coisificam a mulher, anulando sua importância no contexto social e político.

Ao discutir essa categoria Weber (2005), em seu livro Economia e sociedade, enfatiza que o patriarcado retrata uma situação em que a dominação é exercida por uma só pessoa, em geral o pai, chefe de família que de acordo com regras estabelecidas hereditariamente e fundamentada, na maioria das vezes, pelo domínio da condição econômica, esse pai ou chefe de família mantém uma relação de total domínio e poder sobre os demais membros da família ou sobre a comunidade em que vive.

Weber nos explica ainda que essa dominação se mantém apoiada em bases jurídicas onde se funda a legitimidade. Em relação às mulheres essa dominação também se sustenta através dos preceitos religiosos que, dependendo da interpretação do grupo ou tendência religiosa, reforça a submissão das mulheres e seu enclausuramento ao mundo doméstico. 
Por fim, é importante ressaltar que a dominação patriarcal se sustenta na crença da supremacia masculina, nos poderes senhoriais dos homens, vistos como senhores que ordenam e súditos que aprendem desde cedo a obedecer-a partir de uma tradição forjada na cultura, na educação das crianças, passado de geração em geração. (WEBER, 2005, p.184). Isso explica, em grande parte, a situação de subalternidade em que se encontram as mulheres que por não terem seu trabalho valorizado, ficam à mercê da relação de domínio do marido, que se vê como provedor e, por esta razão, exerce o poder de mando e domínio sobre as mulheres e as crianças.

Uma boa contribuição para o debate sobre patriarcado vem das teorias de Patemam (1993) no seu livro: "O contrato sexuaf'. A autora traz as concepções dos liberais contratualistas de que os homens nascem livres e são iguais entre si, são indivíduos dotados de direitos políticos que têm discernimento e, portanto, podem fazer suas escolhas através da razão, não mais por explicações místicas, como era nos regimes patriarcais em que o poder do patriarca era justificado pela tradição, sendo então o patriarcado abolido pelas sociedades modernas capitalistas de forma gradativa. Porém, Pateman (1993) afirma que isso não se sucedeu uma vez que o patriarcado se restabeleceu na sociedade moderna se reconstituindo nas relações afetivas e no confinamento das mulheres ao mundo do privado.

No seu livro Pateman (1993) critica o contrato social de Jean Jacques Rousseau ao dizer que a história do contrato social é apresentada como uma história de liberdade, em que os homens, no estado natural, trocam as inseguranças pela liberdade civil salvaguardada pelo Estado. No contrato sexual de Pateman, a autora reflete a história da sujeição, dominação dos homens sobre as mulheres, na qual o direito masculino se efetiva no livre acesso aos corpos das mulheres, no cerceamento de sua liberdade civil e se traduz nos limites impostos pelos liberais que, desde o princípio, limitou os direitos das mulheres, não os universalizando.

A história do contrato sexual é sobre relações (hetero) sexuais e sobre mulheres personificadas como seres sexuais. A história nos ajuda a compreender os mecanismos através dos quais os homens reivindicam os direitos de acesso sexual e de domínio dos corpos das mulheres. Além disso, as relações heterossexuais não estão limitadas à vida privada. (PATEMAN, 1993, p. 36).

Desse modo, podemos afirmar que o conceito de patriarcado explica os processos de exclusão das mulheres na sociedade, permite compreender como a diferença sexual tem sido convertida em diferença política para naturalizar a sujeição das mesmas. Explica também como a condição de dependência econômica das mulheres contribui para mantê-las subjugadas ao marido, ou companheiro. Através do patriarcado é possível compreender como os homens constroem suas relações de domínio sobre as mulheres na medida em que se representam acima das mesmas, anulando suas iniciativas e singularidades. Para Beauvoir (1986, p.13):

O homem representa a um tempo o positivo e o neutro, a ponto de dizermos "os homens" para designar os seres humanos, tendo-se assimilado ao sentido singular do vocabulário vir o sentido geral da palavra homo. A mulher aparece como negativo, de modo que toda determinação Ihe é imputada como limitação, sem reciprocidade. 
As ideias expressas por Beauvoir (1986) permitem compreender o processo de impedimento da presidenta Dilma Rousseff coordenado por homens que sempre dominaram o cenário político brasileiro. São homens que representam a elite conservadora que não concebe as mulheres enquanto sujeito político.

\title{
2.2 A sub-representação das mulheres no Brasil e seus reflexos no Golpe de 2016
}

A sub-representação feminina é um conceito que denota a discrepância entre eleitorado feminino e o número de mulheres eleitas. No Brasil está relacionada aos números ínfimos de mulheres eleitas nos pleitos para os diversos cargos de poder e representação, considerando, ser as mulheres, maioria do eleitorado no país.

Ao afirmar que as mulheres são sub-representadas o fazemos a partir dos dados eleitorais quando se percebe que apenas $9,8 \%$ das mulheres que se candidataram foram eleitas para a Câmara Federal nas eleições de 2014. A sub-representação feminina é reflexo das condições que precedem os pleitos eleitorais: está nas relações patriarcais de convivência nos partidos, fator determinante com o intuito de desestimular a presença das mulheres nos campos de decisão partidária, está também na cultura do silêncio que lhes foi imposta e na educação de gênero, que impõe às mulheres assim como aos homens, valores que subestimam as mulheres, desqualificam sua opinião e desestimulam seu exercício de cidadã. Para Ferreira (2015, p. 215):

\begin{abstract}
A sub-representação feminina também está relacionada, entre outros fatores, a resistências e preconceitos presentes nas organizações partidárias, no acesso seletivo aos recursos econômicos e sociais. Isso é perfeitamente passível de comprovar pelos valores arrecadado pelas mulheres nas campanhas eleitorais em relação aos homens.
\end{abstract}

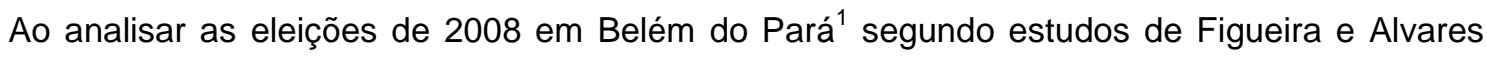
(2012) as mulheres arrecadaram apenas $10 \%$ dos recursos privados em relação aos homens. Esses dados ajuízam a realidade das eleições de todos os Estados brasileiros. Segundo os pesquisadores "Hoje quem financia as campanhas é um conjunto de interesses privados. Essas candidaturas [de negros, índios e mulheres] normalmente são minoritárias, têm menos recursos e menos espaço na mídia". (FIGUEIRA; ALVARES, 2012, p. 234).

Nas eleições de 2018, com o fim do financiamento privado das campanhas, os Partidos passaram a receber recursos para financiar as campanhas eleitorais de seus candidatos, embora ainda seja prematura para avaliar os resultados finais destas eleições, entretanto, muitas mulheres que se candidataram denunciaram seus partidos pela discriminação da distribuição dos recursos públicos nessa eleição.

Para entender a sub-representação das mulheres na política brasileira é importante não perder de vista as relações patriarcais, como mencionado no item anterior, e os preconceitos de gênero,

\footnotetext{
${ }^{1}$ Estou me referindo a Capital do Estado do Pará que fica no Norte do Brasil.
} 
marcas da discriminação sexual que são submetidas as mulheres de forma irracional. O tratamento discriminatório, obcecado pelas diferenças entre homens e mulheres, não deveria ser justificado com suporte em diferenças sexuais, uma vez que esta tem sido uma das justificativas para mantê-las distanciadas dos espaços de poder.

Os discursos recorrentes na sociedade veicularam a crença de que: "as mulheres não gostam de política", ou "as mulheres não sabem fazer política". Mas, falta a sociedade debater sobre se as mulheres têm tempo de fazer política partidária e sindical, por exemplo, a sobrecarga de trabalho, a dupla jornada de trabalho e a forma como os partidos se organizam, excluem as mulheres deste tipo de atividade e dificulta seu reconhecimento enquanto protagonistas. Isso apenas confirma o fato de que os preconceitos e os estereótipos tradicionais a respeito dos supostos papéis atribuídos aos homens e às mulheres ainda continuam a ser regra em toda a conjuntura social. Ao comentar o problema Ferreira (2015, p. 221) enfatiza ainda que:

O aprisionamento das mulheres ao mundo doméstico, mesmo quando exercem atividades fora de casa, tem contribuído para o afastamento das mulheres da política formal e dos partidos. Embora muitos avanços tenha ocorrido neste sentido, especialmente acerca dos arranjos familiares, as tarefas domésticas e a socialização e inserção dos filhos permanecem como atribuições das mulheres, e este é um dos principais empecilhos para sua inserção na vida partidária, caminho que leva aos cargos de representação política.

Além dessas explicações acima mencionadas, a pesquisadora Ana Alice Costa (1999) acrescenta que a baixa representação feminina está relacionada à construção do processo liberal democrático que não consegue perceber as mulheres como parte da sociedade. Além disso, a conquista tardia do voto feminino também influenciou no imaginário social a ideia de que política e voto não são compatíveis com as mulheres.

Os esforços das mulheres brasileiras para alterar as desigualdades de gênero na política se intensificaram no final do século $X X$, quando os movimentos feministas passaram a fazer veladas críticas e a questionar o "Estado democrático" e a exclusão das mulheres nos espaços de poder. Ao questionarem o "Estado democrático" as feministas denunciavam a sub-representação das mulheres na política trazendo ao mesmo tempo um conjunto de questões ainda não atendidas pelo Estado brasileiro. Vale destacar que é na década de noventa que as primeiras ações efetivas começam a ser implementadas para mudar o quadro de desigualdade de gênero na política. Isto se dá com a inserção de cotas de $25 \%$ para um sexo diferenciado em 1995. Dois anos depois, Lei № 9.504, de 30 de setembro de 1997 que estabelece normas para as eleições daquele ano. Nesta Lei a política de cotas é alterada para 30\%, entretanto, não foi efetivado garantias para o cumprimento das legislações que criaram a políticas de cotas para a igualdade de gênero no Brasil.

Mas, é importante ressaltar que a situação das mulheres passou a ter maior atenção com a eleição de Luiz Inácio Lula da Silva, eleito em 2002. Ao definir seu ministério esse presidente indica várias mulheres para assumir postos nos Ministérios, houve então um aumento real de representação feminina em cargos decisórios e maior reconhecimento das mulheres no poder. Quatro mulheres assumem cargos no Ministério de Lula: Benedita da Silva - Assistência e Promoção Social; Dilma 


\section{Rousseff - Minas e Energia; Marina Silva - Meio Ambiente; Emília Fernandes - Secretaria Nacional de Direitos da Mulher.}

É importante lembrar que nos governo de Itamar Franco (1992-1994), a única mulher a assumir de fato uma pasta foi Luiza Erundina, que comandou a Secretaria de Administração Federal por 5 meses após a saída de Osíris de Azevedo. No governo de Fernando Collor (1990-1992) duas mulheres assumem cargos ministeriais: Margarida Maia Procópio que assumiu o Ministério da Ação Social e Zélia Cardoso de Mello que assumiu o importante Ministério da Economia, Fazenda e Planejamento, fato que causou grande repercussão no cenário político brasileiro de então.

A ascensão de Dilma Rousseff na política brasileira se dá quando o Presidente Luiz Inácio Lula da Silva Ihe indica para o Ministério Minas e Energia e, posteriormente, para o Ministério da Casa Civil em substituição ao ex-ministro José Dirceu. Segundo notícias veiculadas na imprensa e entrevista de auxiliares mais diretos o estilo "trator" de Dilma, e sua fama de durona e trabalhadora ganhou pontos com Lula por ter, na visão dele, colocado o setor energético "em ordem" após o apagão de 2001 durante o governo de Fernando Henrique Cardoso. Os comentários da imprensa são bem ilustrativos quando da nomeação de Dilma em 2005:

Será a primeira mulher a chefiar a Casa Civil na história. Dirceu avalia que Dilma tem um perfil "desenvolvimentista" e pode manter contraponto ao "monetarista" ministro da Fazenda, Antônio Palocci Filho, que chegou a ser cogitado para a Casa Civil. Apesar de esses rótulos serem uma definição pouco precisa, Dirceu e a cúpula do PT avaliaram que a escolha de Dilma evitaria a concentração hegemônica de poderes em Palocci. (ALENCAR, 2005, p.1).

É importante ressaltar que a nomeação de Dilma Rousseff, em 2003, para Ministra das Minas e Energia, surpreendeu por ser uma mulher pouco conhecida no cenário nacional, e por não pertencer aos quadros tradicionais do Partido dos Trabalhadores, porém, suas falas pontuais na construção do Programa de Aceleração do Crescimento - PAC e nos projetos envolvendo energia elétrica repercutiam de forma positiva no cenário político. Sua nomeação em 2005 para Ministra da Casa Civil consolida seu poder junto ao Presidente Lula. As matérias jornalistas veiculadas pela grande imprensa nacional e internacional em 2005 reforçaram uma imagem de mulher forte e competente.

Sua indicação para suceder Lula na eleição de 2010 refletiu seus esforços na coordenação dos principais projetos de desenvolvimento do País, entre os quais o Pacto de Aceleração de Crescimento PAC que se constituiu como um plano audacioso do governo federal para estimular o crescimento da economia brasileira, através do investimento em obras de infraestrutura (portos, rodovias, aeroportos, redes de esgoto, geração de energia, hidrovias, ferrovias, etc.). Foi responsável por mudanças substanciais na economia e alterou as relações sociais em todo o País.

Ao assumir o mandato de Presidenta em 2011 as mulheres passaram a ter maior expressão no governo de Dilma Rousseff. Nove mulheres são nomeadas para os ministérios: Ideli Salvatti (PT-SC) Ministério da Pesca; Maria do Rosário (PT-RS) - Secretaria de Direitos Humanos; Miriam Belchior (PT-SP) Ministério do Planejamento, Luiza Helena de Bairros (PT) - Secretaria Especial de Promoção da Igualdade Racial, Tereza Campello (PT) - Ministério do Desenvolvimento Social, Iriny Lopes (PT-ES) - Secretaria Especial e Políticas para as Mulheres, Izabella Teixeira - Meio Ambiente, Ana de Hollanda - Ministério da 
Cultura e Helena Chagas - Secretaria de Comunicação Social. As críticas que recebeu quando a nomeação das mulheres denotam a real dimensão do conservadorismo da imprensa e de outras instituições nacionais.

\subsection{A sub-representação das mulheres no Congresso Nacional e seu reflexo sobre o Golpe de 2016}

Ao observamos com mais atenção o quadro de mulheres e homens eleitos em 2014, constatamos que as mulheres não conseguiram ocupar nem mesmo $10 \%$ das 513 cadeiras que compõe a Câmara Federal. A Tabela 1 demonstra que a ascensão das mulheres no Legislativo Federal é lenta.

É visível a sub-representação das mulheres na política brasileira. O número pouco representativo de mulheres eleitas surpreende, também, em virtude das políticas públicas de igualdade de gênero que foram investidas tanto nos dois mantados de Luiz Inácio Lula da Silva, (2003-2006; 2007-2010), assim como no primeiro mandato do governo Dilma (2011-2014). Surpreende inclusive, pelo fato de que em praticamente toda a América Latina as mulheres terem superado os indicadores de sub-representação: Argentina, México, Costa Rica, Bolívia, Equador entre outros países as mulheres alcançaram patamares que aproximou as mulheres da paridade política. Na Bolívia as mulheres representam no atual contexto $53 \%$ do Congresso daquele país.

Tabela 1 - Representação feminina na Câmara Federal no Brasil - 1995-2018.

\begin{tabular}{|l|l|l|l|}
\hline $\begin{array}{l}\text { PERIODO } \\
\text { LEGISLATIVO }\end{array}$ & DEPUTADAS & DEPUTADOS & TOTAL \\
\hline $2015-2018$ & 51 & 462 & 513 \\
\hline $2011-2014$ & 45 & 468 & 513 \\
\hline $2006-2010$ & 45 & 468 & 513 \\
\hline $2003-2006$ & 42 & 471 & 513 \\
\hline $2002-1999$ & 28 & 485 & 513 \\
\hline $1998-1995$ & 34 & 479 & 513 \\
\hline TOTAL & 255 & 2833 & \\
\hline
\end{tabular}

Fonte: Dados Pesquisa Mary Ferreira, 2018.

A tabela 1 mostra a lentidão como esse processo vem se alterando no Congresso Brasileiro e a dificuldade das mulheres conquistarem os espaços, considerados ainda inacessíveis a exemplo da política. Observamos que em 1994 foram eleitas 34 mulheres e 479 homens o que corresponde a apenas $7,4 \%$, ou seja, em vinte anos as mulheres praticamente não alteraram as relações patriarcais dentro da política brasileira. Acreditamos que uma maior presença feminina na política impactaria muito na formulação de políticas públicas. Nos estudos que realizamos com vereadoras e vereadores, em sete município maranhenses, constatamos que os projetos que beneficiam mais 
diretamente a população feminina foram iniciativas de vereadoras. Um número maior de mulheres na Câmara Federal também impactaria diretamente em questões de políticas públicas, ou seja, daria mais atenção a situações do déficit das creches, da descriminalização do aborto, no aumento da licença de paternidade, nas campanhas de combate a violência de gênero, entre outras questões que afetam a população feminina. (FERREIRA, 2010; 2015; 2017).

O número pouco representativo de mulheres eleitas em 2014, e um número expressivo de evangélicos, latifundiários e policiais eleitos que passaram a constituir a "bancadas da bala", grupo ultraconservador que dominou o Congresso Brasileiro na gestão de Dilma Rousseff, contribuiu em grande parte para o desgaste do governo, culminando com o golpe de 2016 mascarado de impeachment. Na tabela II podemos observar com mais clareza como foi sendo construído o golpe de 2016, passo a passo. Esse golpe teve desdobramentos inesperados que hoje colocam em risco a democracia brasileira com a eleição de Jair Bolsonaro do PSL. A eleição deste Presidente ultraconservador, eleito em clima de grandes conflitos, coloca em risco os ganhos políticos conquistados nos governos de Lula Inácio Lula da Silva e Dilma Rousseff, e abre uma possibilidade real de aprovação das contrarreformas que desorganizam a vida social e põe em risco a vida de milhares de brasileiros que dependem dos programas sociais implementados nos governos mencionados.

Tabela 2- Os Passos na Construção do Golpe de 2016 que destituiu a Presidenta Dilma Rousseff

\begin{tabular}{|c|c|}
\hline & O GOLPE DE 2016: O PASSO A PASSO (2013-2015) \\
\hline $\begin{array}{l}\text { Junho } \\
2013\end{array}$ & O Brasil prepara-se para a Copa das Confederações. \\
\hline $\begin{array}{l}05 \text { de } \\
\text { junho }\end{array}$ & $\begin{array}{l}\text { Reportagens de Glenn Greenwald para o The Guardian com base em documentos obtidos } \\
\text { por Edward Snowden, ex-consultor da NSA (Agência de Segurança Nacional dos EUA), } \\
\text { revelam extenso programa de vigilância norte-americano com monitoramento das } \\
\text { comunicações } \\
\text { pessoais e corporativas, tanto nos Estados Unidos quanto no exterior. }\end{array}$ \\
\hline $\begin{array}{l}06 \text { a } 13 \\
\text { junho }\end{array}$ & $\begin{array}{l}\text { Manifestações contra o aumento da tarifa de transporte público em São Paulo, } \\
\text { organizadas pelo Movimento Passe Livre sofrem violenta repressão da PM. }\end{array}$ \\
\hline $\begin{array}{l}17 \text { e } 20 \\
\text { junho }\end{array}$ & $\begin{array}{l}\text { Grandes manifestações em capitais e outras cidades por melhorias nos serviços públicos, } \\
\text { contra gastos na Copa de } 2014 \text { e contra a corrupção. Cobertura da grande mídia em } \\
\text { tempo real, } \\
\text { com mudança da avaliação negativa inicial e crescente apoio às manifestações. Primeiros } \\
\text { sinais de rejeição às bandeiras de partidos políticos. }\end{array}$ \\
\hline $\begin{array}{l}24 \text { de } \\
\text { junho }\end{array}$ & $\begin{array}{l}\text { Após reuniões com ministros, governadores e prefeitos e ainda com sindicalistas, } \\
\text { líderes de movimentos sociais e membros do Movimento Passe Livre, Dilma anuncia } \\
\text { cinco pactos } \\
\text { nacionais: pelo transporte público, reforma política e combate à corrupção, pela saúde } \\
\text { pública (criação do Programa Mais Médicos), educação ( } 100 \% \text { dos royalties do petróleo, } \\
50 \% \text { do pré-sal) e responsabilidade fiscal. }\end{array}$ \\
\hline $\begin{array}{l}30 \text { de } \\
\text { junho }\end{array}$ & $\begin{array}{l}\text { Após o fim da Copa das Confederações, a mídia volta a enfocar atos de violência e } \\
\text { vandalismo das manifestações, apoiando a repressão das PMs aos manifestantes. }\end{array}$ \\
\hline $\begin{array}{l}2 \text { de } \\
\text { Julho }\end{array}$ & $\begin{array}{l}\text { Dilma apresentou ao Congresso temas para a elaboração de plebiscito sobre a reforma } \\
\text { política: financiamento de campanha, sistema eleitoral, coligações partidárias, fim do voto } \\
\text { secreto no Congresso e fim da suplência de senador. O PMDB não apoiou a iniciativa, que } \\
\text { foi } \\
\text { rejeitada na Câmara dias depois. }\end{array}$ \\
\hline
\end{tabular}




\begin{tabular}{|c|c|}
\hline $\begin{array}{l}1^{\circ} \text { de } \\
\text { setembro }\end{array}$ & $\begin{array}{l}\text { Reportagem do Fantástico (Rede Globo) com base em documentos da NSA próximos em } \\
2011 .\end{array}$ \\
\hline \multirow[t]{2}{*}{$\begin{array}{c}8 \mathrm{de} \\
\text { setembro }\end{array}$} & $\begin{array}{l}\text { Nova reportagem do Fantástico revela que a Petrobrás era espionada. } 24 \text { de setembro - } \\
\text { Presidenta Dilma critica espionagem americana em seu discurso na abertura da } \\
\text { Assembleia Geral da ONU. }\end{array}$ \\
\hline & 2014 \\
\hline Março & $\begin{array}{l}\text { Deflagrada a fase ostensiva da Operação Lava Jato, que investiga a Petrobrás. } \\
\text { Setembro e outubro - A Lava Jato é utilizada na mídia contra Dilma na campanha } \\
\text { eleitoral. }\end{array}$ \\
\hline $\begin{array}{c}6 \text { de } \\
\text { outubro }\end{array}$ & Primeiro turno das eleições, Congresso eleito é o mais conservador desde 1988 \\
\hline \multirow[t]{2}{*}{$\begin{array}{l}26 \text { de } \\
\text { outubro }\end{array}$} & $\begin{array}{l}\text { Segundo turno das eleições presidenciais. Dilma reeleita com mais de } 54 \text { milhões de } \\
\text { votos. }\end{array}$ \\
\hline & 2015 \\
\hline $\begin{array}{c}1^{\circ} \text { de } \\
\text { fevereiro }\end{array}$ & $\begin{array}{l}\text { Eleição de Eduardo Cunha para a presidência da Câmara dos Deputados, com apoio da } \\
\text { oposição a Dilma. Estratégia é de inviabilizar o governo de Dilma. }\end{array}$ \\
\hline $\begin{array}{l}15 \text { de } \\
\text { março }\end{array}$ & $\begin{array}{l}\text { Manifestações contra o governo de Dilma e contra a corrupção mobilizam quase um } \\
\text { milhão de manifestantes em mais de } 150 \text { municípios brasileiros, convocados pelo } \\
\text { Movimento Brasil Livre (MBL), Vem pra Rua, Revoltados Online, partido Solidariedade e } \\
\text { SOS Forças Armadas. }\end{array}$ \\
\hline $\begin{array}{l}19 \text { de } \\
\text { março }\end{array}$ & $\begin{array}{l}\text { Senador José Serra apresenta PL 131/2015, com vistas a alterar o regime de exploração } \\
\text { do } \\
\text { pré-sal. Em 2010, Wikileaks havia revelado conversas de José Serra com lobistas do } \\
\text { petróleo. }\end{array}$ \\
\hline $\begin{array}{l}8 \text { de } \\
\text { abril }\end{array}$ & $\begin{array}{l}\text { Votação do PL 4330/2004 na Câmara dos Deputados alcança } 324 \text { votos contra 137. O } \\
\text { projeto de lei libera a terceirização dos contratos de trabalho para as atividades-fim das } \\
\text { empresas. Entidades de trabalhadores denunciam a ameaça aos direitos trabalhistas. }\end{array}$ \\
\hline $\begin{array}{l}5 \text { de } \\
\text { setembro }\end{array}$ & $\begin{array}{l}\text { Conferência Nacional Popular em Belo Horizonte, criação da Frente Brasil Popular } \\
\text { reunindo MST, CUT, UNE, UBES, UJS, Levante Popular da Juventude, CPT, Fórum 21, } \\
\text { Via Campesina, } \\
\text { Marcha Mundial das Mulheres, Movimento da Reforma Sanitária e dezenas de outros } \\
\text { movimentos sociais. Lançamento do Manifesto ao Povo Brasileiro pregando a união em } \\
\text { torno da defesa da democracia, soberania nacional, integração regional e } \\
\text { combate ao neoliberalismo. }\end{array}$ \\
\hline $\begin{array}{l}4 \text { de } \\
\text { novembro }\end{array}$ & $\begin{array}{l}\text { Parecer favorável em Comissão Especial para a PEC 99/2011 que confere às } \\
\text { organizações } \\
\text { religiosas direitos restritos a determinados representantes do Estado, como o de } \\
\text { propor Ações Diretas de Inconstitucionalidade (ADIN) ao Supremo. }\end{array}$ \\
\hline $\begin{array}{l}11 \mathrm{de} \\
\text { novembro }\end{array}$ & $\begin{array}{l}\text { Instalação de CPI na Câmara para investigar a atuação da FUNAI e do INCRA na } \\
\text { demarcação de terras indígenas e de remanescentes de quilombos. }\end{array}$ \\
\hline $\begin{array}{l}\text { Novembro } \\
\text { de } 2015\end{array}$ & $\begin{array}{l}\text { Movimento de estudantes secundaristas ocupa mais de } 200 \text { escolas contra } \\
\text { projeto de reorganização proposto pelo governo de Geraldo Alckmin e consegue recuo. } \\
\text { Dezenas de escolas ocupadas também em Goiás contra projeto de privatização do } \\
\text { ensino. }\end{array}$ \\
\hline $\begin{array}{l}2 \text { de } \\
\text { dezembro }\end{array}$ & $\begin{array}{l}\text { Presidente da Câmara, Eduardo Cunha, autoriza a abertura de processo de impeachment } \\
\text { de Dilma, em retaliação ao apoio do PT ao processo de cassação de seu mandato, com } \\
\text { base nas } \\
\text { informações de contas não declaradas na Suíça. }\end{array}$ \\
\hline $\begin{array}{l}13 \text { de } \\
\text { dezembro }\end{array}$ & $\begin{array}{l}\text { Manifestação a favor do impeachment de Dilma Rousseff, com apoio da FIESP, no dia do } \\
\text { aniversário da aprovação do Ato Institucional número } 5 \text { (Al-5), em 1968, que consolidou a } \\
\text { ditatura civil militar no Brasil. }\end{array}$ \\
\hline $\begin{array}{l}16 \text { de } \\
\text { dezembro }\end{array}$ & $\begin{array}{l}\text { Manifestações reúnem indígenas em Brasília contra a PEC 215/2000 que propõe } \\
\text { que seja exclusividade do Congresso a demarcação de terras indígenas e de } \\
\text { remanescentes de quilombos. }\end{array}$ \\
\hline
\end{tabular}

Fonte: Elaborado pela autora a partir de dados e informações disponíveis nas redes sociais 
A tabela dois revela bastidores do governo e demonstra o passo a passo da construção do golpe. Seu desdobramento foi capitaneado a partir de três frentes: parlamentares da direita, em especial os que representavam a "bancada da bala", conforme mencionado, a mídia, liderada principalmente pela Rede Globo e Rede Record que pertence ao maior político evangélico do país, proprietário da Igreja Universal do Reino de Deus e ainda a Revista Veja, baluarte do Golpe de 1964 e Rádio Jovem Pan que prega diuturnamente um discurso fascista contra os Partidos de Esquerda. Aliado a esses dois grandes grupos se soma o Poder Judiciário, capitaneado pelo Supremo Tribunal Federal que funcionou como um tribunal de exceção, e seguiu as ordens da elite econômica que se fez claramente presente pela Federação das Indústrias do Estado de São Paulo - Fiesp e seu pato amarelo e pelos seus adeptos, como Paulo Lemman $(2015)^{2}$, o homem mais rico do Brasil que se prevaleceu do golpe para aumentar mais ainda sua enorme fortuna com a compra de parte das ações da Eletrobrás. Essa empresa nacional foi privatizada pelo governo de Temer, logo que assumiu o governo após o impeachment, em um processo criticado por vários setores da sociedade, conforme pode ser observado nas matérias veiculadas na imprensa ${ }^{3}$ a exemplo de Barrocal ${ }^{4}$ que classifica a privatização de negociata.

\section{Considerações finais}

A proposta desse texto foi discutir como a cultura patriarcal impregnada nas instituições políticas interfere na representação das mulheres. No Brasil essa cultura foi visível em todo processo que culminou com o impeachment da Presidenta eleita Dilma Rousseff. Porém, não se pode desconsiderar que a lentidão com que as mulheres vêm ascendendo nos espaços de poder a exemplo dos legislativos, refletiu de forma substancial no golpe de 2016. Em estudo recentemente publicado na Revista Diálogos Insubmissos ${ }^{5}$ discuto com mais detalhes o processo do impeachment e a forma como a imagem da Presidenta foi senda desgastada paulatinamente, pela grande imprensa e pela classe política conservadora, composta majoritariamente por homens brancos, embora se perceba que em todo o processo que muitas mulheres que compunham a bancada de senadoras $\mathrm{e}$ deputadas também contribuiu para o desgaste da presidenta. $O$ exemplo mais ilustrativo desta ação denominada por alguns atores políticos como o Dia da Vergonha Nacional foi o processo de aprovação do golpe. Uma vez que o que se viu foi:

O espetáculo político mais caricato já visto no plenário daquela casa legislativa,denota o quão vergonhoso foi ouvir deputados defendendo suas famílias, seus redutos políticos, em nome de uma democracia que nenhum deles acreditava e que era visível em seus semblantes. Alguns deles tiveram que engolir sua afronta ao ser preso na semana seguinte por corrupção depois de declarar que votava pela ética. (FERREIRA, 2018, p.72).

\footnotetext{
2 Jorge Paulo Lemann é quem financia o golpismo? (2015)

${ }^{3} \mathrm{Na}$ privatização da Eletrobrás, incompetência e irresponsabilidade. Carta Capital. (2018)

${ }^{4}$ BARROCAL, André. O cheiro de negociata na privatização da Eletrobrás. Carta Capital. 2017

${ }^{5}$ Estou me referindo ao texto: Movimentos feministas no Brasil e sua ação insubmissa frente ao golpe de 2016 , disponível no site: https://periodicos.ufpe.br/revistas/debatesinsubmissos/article/view/237868.
} 
Os desdobramentos após o golpe tem nos mostrado que este episódio não se encerrou naquele momento, o processo de demonização das esquerdas e em especial do Partido dos Trabalhadores, vai trazer um profundo desalento para os setores mais progressistas da sociedade. Observamos que houve um acirramento das relações patriarcais, na medida em que foi sendo forjada a candidatura de Jair Bolsonaro, eleito de forma surpreendente pelos brasileiros.

A candidatura de Bolsonaro trouxe a público a desqualificação dos grupos minoritários: mulheres, negros e indígenas. As ameaças feitas de forma direta, o discurso de ódio estimulado pela candidatura deste militar, arregimentou brasileiros principalmente no sul e sudeste do Brasil. Frases do tipo: "mulher tem que ganhar menos porque engravida" surtiu um efeito negativo na candidatura, porém, não impediu que ele fosse eleito.

Podemos, então, concluir enfatizando que a eleição do atual Presidente da República do Brasil coroa o conservadorismo patriarcal da sociedade brasileira, embora saibamos que muitos elementos podem ser agregados nesse debate para ampliar as análises sobre o momento que vivenciamos nos últimos anos que reflete como o processo foi construído paulatinamente.

Por fim, é importante ainda ressaltar que ao lado destas questões mencionadas, destacamos os atos de resistências protagonizados pelos movimentos feministas em todo País, movimentos como ELE NÃO! Construído das lutas feministas no Brasil, se espraiou por vários países da Europa e África, mostrando a solidariedade feminista no mundo e a preocupação com os destinos dos brasileiros.

\section{Referências}

ALENCAR, Kennedy. (2005). Lula confirma Dilma para a vaga de Dirceu na Casa Civil. Folha de São Paulo, 21 de junho de $2005 . \quad$ Disponível em: <https://www1.folha.uol.com.br/fsp/brasil/fc2106200502.htm> Acesso em 30 out. 2018.

BRASIL, LEI № 9.504, DE 30 DE SETEMBRO DE 1997. Estabelece normas para as eleições. Diário Oficial da União, Brasília, 30 de setembro de 1997. Disponível em:< http://www.planalto.gov.br/ccivil 03/leis/L9504.htm>

BEAVOIR, Simone. (1986). O segundo sexo: fatos e mitos. São Paulo: Circulo do Livro, 1986.

BIROLI, Flávia. Gênero e Desigualdades: limites da democracia no Brasil. (2018). São Paulo: Boitempo.227p.

COSTA, Ana Alice Alcântara. (Org.) (2009). Trilhas do poder das mulheres: experiências internacionais em ações afirmativas. Brasília: Câmara dos Deputados, Edições Câmara.

FERREIRA, Maria Mary. et. al. (2016) Direitos iguais para sujeitos de direito: empoderamento de mulheres no combate à violência doméstica. São Luís: EDUFMA.

FERREIRA, Maria Mary. et. al. (2018) Movimentos feministas no Brasil e sua ação insubmissa frente ao golpe de 2016. Revista Debates Insubmissos, v. 1, n. 2, maio/ago. 2018, p.55-74.Disponível em: $\quad<$ https://periodicos.ufpe.br/revistas/debatesinsubmissos/article/view/237868/29957>. Acesso em 30 out. 2018

FERREIRA, Maria Mary. (2010). Os Bastidores da Tribuna: mulher, política e poder no Maranhão. São Luís: EDUFMA.

FERREIRA, Maria Mary. (2018). Protagonismo feminino e relações de gênero. Relatório preliminar de Pesquisa financiada pela Fundação de Amparo à Pesquisa, São Luís, 2018. 75p. 
FERREIRA, Maria Mary. (2015) Igualdade de gênero e participação política. In: SOUZA, Cristiane de Aquino. In: Democracia, Igualdade e Liberdade: perspectivas jurídicas e filosóficas. Rio de Janeiro: Lumem Juris. p.211-228.

FERREIRA, Maria Mary. (2015). Vereadoras e Prefeitas maranhense: ação parlamentar sob a ótica de gênero. São Luís: EDUFMA.

FIGUEIRA, Murilo Cristo; ALVARES, Maria Luzia Miranda.(2012) Financiamento Eleitoral: desigualdade de gênero nas eleições do Pará - 2008. In: FERREIRA, Maria Mary. (Org.). Gênero, Política e poder: participação das mulheres nos espaços de poder no Norte e Nordeste. São Luís: EDUFMA, p.225-242.

JORGE Paulo Lemann é quem financia o golpismo? Brasil 247. 9 mar.2015. Disponível em: https://www.brasil247.com/pt/247/economia/172505/Jorge-Paulo-Lemann-\%C3\%A9-quemfinancia-o-golpismo.htm; Quem financia os grupos que pedem o impeachment?

PATEMAN , Carole. (1993) O contrato sexual Sa o Paulo: Editora Paz e Terra.

QUEM financia os grupos que pedem o impeachment? Diário do Centro do Mundo. 13 mar. 2015. Disponível em: <https://www.diariodocentrodomundo.com.br/quem-financia-os-grupos-quepedem-o-impeachment/>. Acesso em 26 jun. 2018.

SAFFIOTI, Helleith lara Bongiovani. (1987). O poder do macho. São Paulo: Moderna.

SAFFIOTI, Heleieth I. B. (2004). Gênero, patriarcado e violência. São Paulo: Perseu Abramo, 2004.151p.

WEBER, Max. (1999). Dominação patriarcal e dominação patrimonial. In: Economia e sociedade. Brasília: UNB, p. 233-256.

WOLLSTONECRAFT, Mary. (2016). Reivindicação dos direitos da Mulher. São Paulo: Boi Tempo. 